\title{
Letter to the Editor concerning: "the non-visualized appendix and secondary signs on ultrasound for pediatric appendicitis in the community hospital setting"
}

\author{
Thomas Rogerson ${ }^{1} \cdot$ Montgommery Do-Wyeld ${ }^{1} \cdot$ Thomas P. Cundy $^{1} \cdot$ Roger Gent $^{1} \cdot$ Day Way Goh $^{1}$
}

Accepted: 22 January 2019 / Published online: 2 February 2019

(c) Springer-Verlag GmbH Germany, part of Springer Nature 2019

\section{Dear Editor,}

We read with interest the recent article by Held et al. that investigated the diagnostic value of secondary sonographic signs for pediatric appendicitis in the circumstance of a nonvisualized appendix [1]. The appendiceal visualization rate (AVR) is considered by many to be reflective of the quality of an ultrasound service. The AVR of $23.8 \%$ in this study is considered low. Numerous studies have reported benchmark standard rates of diagnostic accuracy for ultrasound in pediatric appendicitis, with visualization rates as high as 91.7\% [2-4]. Consistent rates of high AVR are achievable with invested effort in training as well as spending the time required to employ numerous advanced strategies to localize the appendix [2]. These include patient repositioning, distraction techniques, emptying and filling the urinary bladder, and breath-holding manoeuvers [2]. We also strongly recommend a tightly curved array transducer as it allows more targeted graded compression and relative size appropriateness for younger children [2].

This comment refers to the article available online at https://doi. org/10.1007/s00383-018-4350-1.

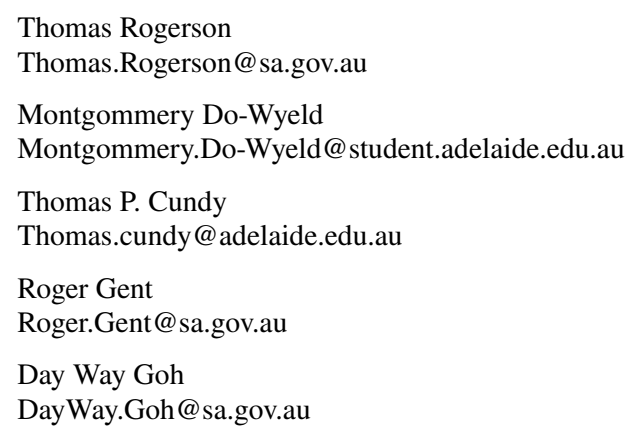

Thomas Rogerson

Thomas.Rogerson@sa.gov.au

Montgommery Do-Wyeld

Montgommery.Do-Wyeld@ student.adelaide.edu.au

Thomas P. Cundy

Thomas.cundy@adelaide.edu.au

Roger Gent

Roger.Gent@sa.gov.au

Day Way Goh

DayWay.Goh@sa.gov.au

1 Department of Paediatric Surgery, Women's and Children's Hospital, 72 King William Street, North Adelaide,

South Australia 5006, Australia
Complete visualization of the vermiform appendix in its entirety is obligatory for an accurate diagnostic examination. We support the authors' acknowledgement that secondary sonographic signs for appendicitis have value as adjuncts to an imaging diagnosis, but stress that these should not be considered a reliable or acceptable substitute for poor quality ultrasound assessment represented by a low appendiceal visualization rate.

Funding No funding was sought or obtained for the writing of this letter.

\section{Compliance with ethical standards}

Conflict of interest The authors declare they have no conflict of interest.

Ethical approval This article does not contain any studies with human participants or animals performed by any of the authors.

Informed consent Not applicable.

\section{References}

1. Held JM, McEvoy CS, Auten JD, Foster SL, Ricca RL (2018) The non-visualized appendix and secondary signs on ultrasound for pediatric appendicitis in the community hospital setting. Pediatr Surg Int 34(12):1287-1292

2. Cundy TP, Gent R, Frauenfelder C, Lukic L, Linke RJ, Goh DW (2016) Benchmarking the value of ultrasound for acute appendicitis in children. J Pediatr Surg 51(12):1939-1943

3. Goldin AB, Khanna P, Thapa M, McBroom JA, Garrison MM, Parisi MT (2011) Revised ultrasound criteria for appendicitis in children improve diagnostic accuracy. Pediatr Radiol 41(8):993-999

4. Baldisserotto M, Marchiori E (2000) Accuracy of noncompressive sonography of children with appendicitis according to the potential positions of the appendix. AJR Am J Roentgenol 175(5):1387-1392 